\title{
Consideraciones en torno a las leyes que protegen el patrimonio cultural en Cuba
}

Ana Daelé Valdés Millán ${ }^{1}$

\section{Introducción}

El início del siglo XX no solamente significó para Cuba el advenimiento de una nueva centuria, sino la disolución de más de cuatro siglos de vínculos coloniales que influyó sustancialmente en las esferas política, económica y social, alcanzando además a la cultura. Si bien la ruptura con el colonialismo español no significó la concreción de la máxima aspiración del pueblo cubano, de alcanzar la absoluta soberanía tras concluir la guerra hispano-cubana con la injerencia militar de los Estados Unidos de América (EE.UU) en la contienda bélica y establecer en la Isla un gobierno interventor, en 1901 se convocó una Convención Constituyente encargada de elaborar la constitución de la naciente república la que con independencia de la Enmienda Platt, ominoso apéndice anexado a la Constitución que le otorgó a Cuba la condición de neocolonia, sí dictó el establecimiento de un Estado independiente oficializado el 20 de mayo de 1902 con reconocimiento internacional.

\footnotetext{
${ }^{1}$ Historiadora, doutorada em Museologia pela ULHT, museóloga no Museu Provincial de Guantánamo daele6604@gmail.com
} 
En este contexto se orientó un proceso de reafirmación identitaria frente a la influencia de los elementos foráneos que comenzaron a introducirse a propósito de la ocupación estadounidense y a expandirse durante la primera mitad del siglo $\mathrm{XX}$, de modo que emergieron instituciones tanto privadas como solventadas por entidades oficiales que se enfocaron en la creación de espacios para el desarrollo intelectual y científico. Conjuntamente, desde el inicio de la República, en el orden gubernamental se incorporaron estructuras competentes a la cultura que de manera progresiva fueron conformando un conjunto de experiencias con las que contó el gobierno revolucionario instaurado en 1959 para proyectar la política cultural en general y el cuerpo legislativo para la protección del patrimonio de la nación en particular.

\section{Instrumentos jurídicos durante la República Neocolonial}

Una de las primeras intenciones desde el punto de vista legislativo para la protección del patrimonio cultural en Cuba fue la promulgación durante el gobierno de Gerardo Machado del Decreto Presidencial no. 1306 del 7 de agosto de 1928, a través del cual se designó la creación de una comisión para impedir la dispersión de la riqueza arqueológica, estipulando los requerimientos para efectuar exploraciones arqueológicas, la formación de colecciones con esta temática, así como vedaba la extracción del país de este tipo de piezas, lo que resultó consecuencia de la conformación de un pensamiento concordante con las trasformaciones que se operaron en la psicología social durante los años de 1920, constituyendo uno de los aspectos significativos que marcaron un giro en el rumbo de la República neocolonial.

Sin embargo la convulsa situación política por la que atravesaba la nación para entonces condicionó que el referido decreto quedara solamente como tinta en papel por lo que la referida comisión no alcanzó a cumplir sus funciones técnicas. No obstante el intento resultó un punto inicial para la reducción de las 
incursiones a sitios arqueológicos, que habían proliferado desde mediados de la centuria decimonónica, sobre todo de expediciones foráneas que con independencia del halo científico de muchas de ellas, a la larga propendían a la depredación del legado de las culturas originarias.

El interés por la protección del patrimonio se extendió a otras dimensiones como el patrimonio edificado. En ese mismo año y como resultado de la Ley promulgada el 24 de julio, le fue conferida la prerrogativa al Presidente de la República de formalizar declaratorias de Monumentos Nacionales, así como "dictar disposiciones para la mejor y más eficaz protección de los sitios e inmuebles históricos" (Arias, 2014, p.27), lo que constituyó un importante aspecto en el paulatino proceso de conformación del cuerpo jurídico para la preservación del patrimonio de la nación y para las sucesivas obras de intervención en sitios y edificaciones con valores patrimoniales.

Desde inicios de los años treinta el panorama cubano estuvo caracterizado por la agudización de las tensiones políticas e ideológicas que condujeron a una situación revolucionaria que alcanzó el punto álgido en 1933 con el derrocamiento del gobierno de Gerardo Machado. En sentido general esa década estuvo marcada por una profunda inestabilidad política manifestada en once mandatos presidenciales, sobrepasando los dos o tres períodos que constitucionalmente debían tener lugar en espacio de diez años. En toda esta dinámica estuvieron involucrados diferentes sectores sociales. "En su heterogeneidad socioclasista e ideológica, estas fuerzas expresaban de diversas maneras la conciencia nacional del momento, que aspiraba a la nación independiente, sin la presencia yanqui y a una república decente y justa" (López, 2013, p.104).

En 1934, en el contexto del gobierno de Carlos Mendieta se fundó la Dirección de Cultura, aún como dependencia de la Secretaria de Educación, al frente de la cual estuvo el escritor José María Chacón y Calvo cuya gestión fue notoria. Durante la misma se aprobó el Decreto Ley No. 613, que constituyó el soporte jurídico 
para formular en el propio año la declaratoria, en La Habana, de Monumento Nacional a la Plaza de la Catedral y edificaciones adyacentes y que además del nivel de declaratoria estableció restricciones en cuanto a las intervenciones que pudieran suscitarse en el conjunto, lo que quedó definido en el segundo artículo, conforme a Emilio Roig de Leuchsenring, (citado por Arias, 2014, p.27) “No podrá efectuarse ninguna reparación ni modificación en la Catedral, o en la Plaza o edificios mencionados (...) sin aprobación expresa del gobierno y previo los asesoramientos artísticos, técnicos y de carácter histórico que se estimen necesarios".

Si bien es de considerar que el referido Decreto constituyó un paso importante para la protección de la herencia arquitectónica colonial en la capital cubana y que fijó la responsabilidad del estado respecto a este particular, el mismo en su condición de ley presidencial quedó circunscrito únicamente a un conjunto determinado de edificaciones sin tan siquiera alcanzar otros importantes exponentes del patrimonio monumental capitalino, lo que en consecuencia resultó expresión de las insuficiencias que en materia de protección patrimonial aun existían en Cuba en la tercera década del siglo XX.

Uno de los activistas importantes del período republicano en lo que respecta a la defensa y protección del patrimonio fue el Dr. Emilio Roig de Leuchsenring, prestigioso intelectual habanero, designado en 1935 Historiador de la Ciudad de la Habana y que a través de su Oficina, oficializada por decreto del alcalde Antonio Beruff Mendieta en 1938, ejecutó una ponderable labor orientada a frenar los proyectos de modernización urbana, muchos de ellos con apoyo gubernamental que comprometían peligrosamente la integridad del patrimonio construido, a través de la promoción de múltiples asociaciones y eventos, surgidos entre las décadas de 1930-1940, que nucleaban a otros tantos defensores de los valores culturales y patrimoniales de la nación, tales como la Sociedad Cubana de Estudios Históricos e Internacionales, la Junta Nacional de Arqueología, los Congresos Nacionales de Historia, el Archivo 
Histórico Municipal, y la Comisión de Monumentos, Edificios y Lugares Históricos y Artísticos Habaneros (CMELHAH), entre otras.

"Todas estas instituciones y eventos promovidos desde La Oficina del Historiador, se convirtieron en caballos de batalla contra la desidia y el abandono oficial de la cultura y devinieron generadoras de una genuina difusión cultural e ilustración de las personas, al tiempo que apoyaron con denuedo la protección del patrimonio histórico"(Alfonso, 2008, p.4)

A pesar de que la operatividad de muchas de estas instituciones estuvo restringida al entorno capitalino debido, en lo fundamental, a que la vorágine intervencionista en inmuebles con valores patrimoniales era mucho más marcada que en el resto del país lo cual respondía a la existencia de "mayor capacidad de inversión y una inclemente especulación inmobiliaria" (Rigol, 2012, p.101), sí se puede afirmar que en la década del 1940 se experimentó una mayor intención de legislar la protección del patrimonio.

En este sentido el principal instrumento fue la Constitución de 1940, considerada progresista para la época en tanto proclamó cambios sustanciales "en la estructura del Estado, los derechos civiles y sociales $y$, en general, modernizó el Estado cubano y plasmó de alguna manera el pacto social indispensable después del proceso revolucionario de los años 30" (López, 2013, p.183). El Estado asumía la completa responsabilidad de la cultura en cualquiera de sus manifestaciones. Respecto a la protección del patrimonio quedó explícito que:

“El Estado regulará por medio de la Ley la conservación del tesoro cultural de la Nación, su riqueza artística e histórica, así como también protegerá especialmente los monumentos nacionales y lugares notables por su belleza natural o por su reconocido valor artístico o histórico" (Constitución de 1940, Artículo 58). 
Por primera vez una constitución cubana contemplaba dentro de su articulado la protección al patrimonio de la nación, constituyendo un paso de avance en lo que a su instrumentación jurídica se refiere en tanto reconocimiento del mismo en su carácter nacional y abarcador, trascendiendo los localismos y limitaciones a determinadas dimensiones respecto a decretos y leyes anteriores, reflejando además la madurez del sentido de pertenencia y del esfuerzo de activistas e instituciones defensoras del acervo cultural cubano. Igualmente en los primeros artículos fueron contemplados elementos de identidad cubana como el idioma y los símbolos patrios, lo que evidencia la consolidación de una conciencia nacional.

No obstante se concuerda con el criterio de que "la base económica y social existente no permitía que se cumplieran tales preceptos, ni facilitaba entonces el disfrute del acervo cultural por las grandes mayorías" (Rigol, 2012, p.100), entre otras razones debido a que una parte considerable e importante de ese acervo estaba concentrado en el sector privado, de manera que la propia constitución al legitimar en su articulado la propiedad privada en su más amplio concepto, limitó el acceso a valiosas colecciones. Indudablemente fue una constitución progresista, pero lastimosamente tampoco tuvo mayores alcances que los del marco teórico en tanto adoleció de un cuerpo legislativo complementario que normara su funcionamiento.

Uno de los principales acontecimientos de la década fue la fundación de la Comisión Nacional Cubana de la Unesco (CNCU) el 17 de noviembre de 1947, mediante el Decreto Presidencial no. 4097 firmado por el presidente Ramón Grau San Martín, contando con el coronel del Ejército Libertador Cosme de la Torriente como presidente fundador e integrada por destacados intelectuales como Juan Marinello, Julio Le Riverend, Alfredo Guevara, Alejo Carpentier y Nicolás Guillén, entre otros. Esta Comisión además de su función vinculante entre Cuba y la Unesco resultó una entidad indispensable para el fortalecimiento del desarrollo cultural, educativo y científico del país. 
La creación de la CNCU constituyó el preámbulo para la inauguración el 24 de febrero de 1950 en La Habana del Centro Regional de la UNESCO para el Hemisferio Occidental (CRUHO), cumpliendo los acuerdos de la Conferencia General celebrada en Beirut en 1948. En años anteriores Cuba había sentado un precedente cuando en 1941 la capital fue escenario de la Segunda Conferencia Americana de Comisiones Nacionales de Cooperación Intelectual, cuyo objetivo principal fue establecer en esta ciudad un Centro Internacional de Cooperación Intelectual ante el cese, un año antes, de la actividad del Instituto Internacional de Cooperación Intelectual debido a la ocupación de la ciudad de París, sede del organismo, durante el conflicto bélico. Por otro lado es conveniente considerar el hecho de que para aquel entonces el Director General de la UNESCO, el escritor mexicano Jaime Torres Bodet, tenía especial empatía con Cuba además de una formación sustentada en la obra y pensamiento de José Martí, lo que el propio Torres Bodet manifestó en un mensaje enviado a propósito del acto inaugural del $\mathrm{CRUOH}$ :

"En las tierras de Cuba, el Centro que inauguráis encontrará, estoy seguro, estímulos y fervores. ¿No es Cuba, acaso, la patria magnífica de Martí? Bajo símbolo tan augusto, no podrán sino prosperar los ideales pacíficos de la UNESCO. Porque la paz que propaga la educación, que la ciencia defiende y que la cultura derrama en caudal de belleza eterna, representa para los hombres esa victoria que no se mide, como quería precisamente José Martí, por "la suma de armas en la mano", sino por "el número de estrellas en la frente" (García, 1964; 7)

No por casualidad fue escogida la fecha del 24 de febrero, de gran significación simbólica para Cuba, en homenaje al cincuenta y cinco aniversario del levantamiento que dio inicio a la última de las gestas independentistas del siglo XIX. El primer presidente del Centro, el pedagogo panameño Octavio Méndez Pereira, enfatizó en el desempeño del mismo encaminado al fortalecimiento de las 
relaciones entre los pueblos, su bienestar general y elevar la condición moral de los grandes grupos humanos.

"La obra que se nos ha encomendado será lenta y difícil, como que es fundamentalmente obra de educación, pero como tal también preñada de fe y esperanza, en el destino de nuestra humanidad. Requerirá la comparación y la apreciación de las experiencias alcanzadas en nuestros países en materia de enseñanza fundamental, en las investigaciones científicas y en el campo general y amplio de la cultura, para tratar de encontrar las ideas directrices de una obra de conjunto y sin fronteras y de trazar un plan de servicios eficaces internacionales orientados de acuerdo con nuestras realidades" (García, 1964, p.8).

La manera con que fueron instrumentadas las disposiciones, decretos y leyes de protección al patrimonio de la nación a lo largo de la república neocolonial, con aciertos y desaciertos, constituyó expresión de la consolidación y reafirmación identitaria; del fortalecimiento de una conciencia sobre el significado del papel de la cultura como proceso de construcción colectiva y como mecanismo de defensa del legado histórico.

II. La protección del patrimonio cubano a partir del proyecto social instaurado en 1959.

Con el triunfo revolucionario de 1ro de enero de 1959 se inició la práctica de un nuevo proyecto social en Cuba que implicó la ruptura con el sistema neocolonial que por cincuenta y siete años había gobernado la Isla, a través de reformas radicales en las diversas esferas de la sociedad. Desde esta perspectiva los cambios en las dinámicas cultural y educacional cubanas constituyeron paradigmáticos no solo en el contexto nacional sino en el latinoamericano.

Aún y cuando los primeros años de la década de 1960 fueron de una intensa lucha contra las fuerzas internas y externas que pusieron todo empeño en derrocar la revolución, la estructuración 
de una política cultural acorde a las nuevas circunstancias resultó una de las prioridades del gobierno. De manera que en el contexto de la enconada lucha contra las fuerzas opositoras que operaban en el territorio nacional y las continuadas agresiones estimuladas desde el exterior, principalmente desde los EE.UU, se comenzaron a implementar una serie de medidas aunque todavía no respondían a una política cultural orgánicamente articulada.

Las transformaciones en la cultura serían uno de las más controversiales teniendo en cuenta el papel de la intelectualidad como vanguardia de la sociedad. Se perfiló una política cultural orientada a la ruptura de los esquemas establecidos durante la república neocolonial y al fomento y consolidación de una cultura basada en valores auténticamente cubanos. Como todo proceso revolucionario y transformador, este no escapó a la diversidad de posiciones e interpretaciones que se generaron, desde los que lo apoyaron, los que se opusieron y los que asumieron posturas escépticas, más teniendo en cuenta que una parte considerable de la intelectualidad que llegó al período revolucionario procedía de la burguesía y decidió emprender el camino de la emigración. Otra parte se integró al nuevo proceso, abriéndose una etapa verdaderamente polémica y de agudas confrontaciones ideológicas.

Si bien es cierto que en inicios las trasformaciones fueron acogidas, en mayoría, con entusiasmo, sobre todo entre los años de 1959 a 1961, no demoró mucho tiempo en producirse la ruptura de esa linealidad, sobre todo al proclamarse el carácter socialista de la revolución y luego el fomento de los presupuestos del comunismo, a contrapelo del carácter únicamente democrático declarado inicialmente. Como consecuencia una parte de la intelectualidad cubana que se había destacado durante la primera mitad del siglo XX salió definitivamente del país tales como Lydia Cabrera, Jorge Mañach, Leví Marrero. Otros como Fernando Ortíz, Virgilio Piñeiro, Ramiro Guerra y José Lezama Lima optaron por la permanencia y aunque algunos estudiosos del período revolucionario consideran que ya no contaron con "el liderazgo cívico que durante años habían ejercido" (Barrial y Barrial, 2012) continuaron aportando al que 
hacer cultural. Con independencia de las diferentes posiciones y actitudes adoptadas ante el proceso revolucionario, esta intelectualidad de conjunto dejó una innegable impronta en la cultura cubana.

A partir de esos momentos y bajo tales circunstancias se gestó la política que desde entonces ha regido la dinámica cultural en Cuba, que no está recogida en un único documento sino que está conformada por varios documentos sobre todo discursos del liderazgo político, siendo el más trascendental Palabras a los intelectuales, pronunciado por Fidel Castro Ruz en el marco de una serie de reuniones efectuadas los días 16; 23 y 30 de junio de 1961en el Salón de Actos de la Biblioteca Nacional en la Ciudad de La Habana, en las que participaron las figuras más representativas de la intelectualidad cubana, exponiendo los más variados criterios en torno a aspectos de la actividad cultural, en general, y sobre temas vinculados con la creación artística.

En el discurso, en cuestión, Castro Ruz sentó la línea que seguiría en lo adelante el gobierno revolucionario en pos de lograr una hegemonía cultural, recabando de los artistas todos los esfuerzos a favor del bienestar espiritual del pueblo y en la obra de la Revolución. Con su declaración de que dentro de la Revolución todo, fuera de la Revolución nada (Castro Ruz, 1961), enfatizó el rumbo que tendría en lo adelante la producción artística dentro de los cánones del nuevo sistema, así como la institucionalización de la cultura cubana. Fue entonces la etapa de surgimiento de un número considerable de instituciones encargadas de la promoción y el fomento de los valores culturales y el desarrollo del arte.

El contexto en el que tienen lugar estas transformaciones se pueden resumir en una serie de acontecimientos que apuntaron y apostaron por la desestabilización del proceso revolucionario como la invasión mercenaria a Playa Girón, la Crisis de Octubre o Crisis de los Misiles, la ofensiva de la contrarrevolución interna, la ruptura de las relaciones diplomáticas con los EE.UU y el incremento de la oposición de la intelectualidad a raíz de la declaración del carácter socialista de la Revolución. En esencia los primeros años de triunfo 
de la Revolución Cubana redundaron en agudas confrontaciones entre una generación orientada a la ruptura de la estructura neocolonial y otra que se resistían a la pérdida de sus posiciones.

La actividad museológica que hereda este período de su predecesor republicano se caracterizó por instalaciones que "eran, más que eso, meros almacenes de objetos en los que se mezclaban materiales de gran valor histórico y cultural con otros cuya utilidad no merecía un lugar de exposición" (García, 2014, p.67). A esto se adicionó la manifiesta desactualización de las técnicas museográficas a la usanza del siglo XIX y por supuesto una total ausencia de todo tipo de estudios relacionados con la dinámica museal.

"Los cambios revolucionarios gestados en Cuba a partir de 1959 dieron origen no sólo a una profunda transformación de la proyección social de la museología, y a la consecuente incentivación del rescate y la conservación de valores históricos, artísticos, documentales y arquitectónicos, sino también, necesariamente, a instituciones museísticas diferentes, con una nueva presentación técnica, científica e ideológica consecuente con los principios de la Revolución. En mi opinión, las masas desposeídas, base social del proceso triunfante, clamaban por verse reflejadas en las vitrinas como ejemplo de lo que fueron y no volverían a ser" (García, 2014, p.67)

De conjunto las profundas transformaciones en el contexto sociopolítico, económico y cultura cubano no solamente representaron la ruptura con el esquema republicano sino que también representó asumir retos y desafíos con una fuerte carga de escepticismo. Se carecía de modelos referenciales en el contexto latinoamericano, por lo que el proceso fue tomando forma $y$ definiendo rumbos sobre su propia marcha. El hecho de que el nuevo gobierno colocara el tema de la cultura entre los asuntos prioritarios a encauzar, resultó indicativo de la comprensión del 
papel de la misma como pilar fundamental de la sociedad y como parte de ella el proceso de institucionalización y la atención a los museos como entidades encargadas de contener la memoria histórica de pueblo.

Sin dudas la experiencia acumulada en materia de política cultural en general y de protección al patrimonio en particular durante los años republicanos propició que desde sus inicios el nuevo proyecto social cubano tuviera como plataforma la democratización de la cultura, como herramienta primordial para llevar a vía de hecho las transformaciones que romperían con las estructuras económica, política y social del período anterior. Con una proyección sistémica el gobierno, del cual formaron parte varios activistas y defensores del patrimonio, concibió y emprendió la revolución cultural con plena integración y participación popular, y en concordancia "las grandes líneas de una política de restauración, de protección y de mantenimiento del patrimonio histórico y cultural [de Cuba] fueron trazadas" (Cantón y Duarte, 2006, p.45)

Las principales premisas en materia de cultura y patrimonio quedaron refrendados en la Constitución de la República de Cuba de 1976 resultada del referéndum constitucional llevado a cabo ese mismo año, donde el Estado cubano estableció la accesibilidad a la educación y la cultura como derechos básicos del ser humano.

h) El Estado defiende la identidad de la cultura cubana y vela por la conservación del patrimonio cultural y la riqueza artística e histórica de la nación. Protege los monumentos nacionales y los lugares notables por su belleza natural o por su reconocido valor artístico e histórico;

i) El Estado promueve la participación de los ciudadanos a través de las organizaciones de masas y sociales del país en la realización de su política educacional y cultural. (Constitución de la República de Cuba, 1976, Artículo 39) 
Atendiendo a los postulados de este artículo, el 4 de agosto de 1977 fueron implementadas como las dos primeras leyes de la Asamblea Nacional del Popular la no. 1 De Protección al Patrimonio Cultural, y la no. 2 De los Monumentos Nacionales y Locales, reglamentadas a través de los decretos no. 118 del 23 de septiembre de 1983 y en el no. 55 del 29 de noviembre de 1979 respectivamente, firmados ambos por Fidel Castro en su condición de Presidente del Consejo de Ministros.

En el artículo primero de la Ley no.1 se define el objeto de la misma orientado a la determinación de los bienes que, por su especial relevancia en relación con la arqueología, la prehistoria, la historia, la literatura, la educación, el arte, la ciencia y la cultura en general, integran el patrimonio cultural de la nación, y establecer medios idóneos de protección del mismo. El reglamento establece los niveles de dependencia y responsabilidad de las diferentes entidades e instancias que en lo adelante responderían por la protección de los bienes patrimoniales del país, adjudicándosele la principal responsabilidad al Ministerio de Cultura (MINCULT).

Por su parte en la Ley no.2 se definieron lo que quedaría comprendido en las categorías de Monumento Nacional, entendido como todo centro histórico urbano y toda construcción, sitio u objeto que, por su carácter excepcional, merezca ser conservado por su significación cultural, histórica o social para el país, y Monumento Local a toda construcción, sitio u objeto que, no reuniendo las condiciones necesarias para ser declarado Monumento Nacional por su interés cultural, histórico o social para una localidad determinada.

El otorgamiento de ambas declaratorias deben realizarse bajo el designio la Comisión Nacional de Monumentos (CNM) cuya constitución igualmente quedó legislada, y apoyada en la conformación de las Comisiones Provinciales de Monumentos adscriptas a las Direcciones de Cultura de los Comités Ejecutivos de la Asambleas Provinciales del Poder Popular y subordinadas técnicas y profesionalmente al MINCULT. De igual manera a instancia municipal quedó establecida la organización de las delegaciones 
municipales de monumentos que estarían integradas por uno o más delegados, de acuerdo a las características específicas de cada municipio y subordinados a la CNM, cuyo funcionamiento sería asumido tiempo después por los museos municipales. Como complemento de esta legislación en el código penal fueron contempladas sanciones por delitos contra el patrimonio cultural, resumidas en:

Capítulo I. Daños a Bienes del Patrimonio Cultural.

Capítulo II. Extracción llegal del País de Bienes Patrimoniales.

Capítulo III. Trasmisión, Tenencia llegal de Bienes del Patrimonio Cultural y Falsificación de Obras de Arte.

Capítulo IV. Exploración Arqueológica llegal.

Acorde a los principios legislativos estipulados en el decreto 118 , el patrimonio cultural de la nación está integrado por aquellos bienes muebles e inmuebles, que son la expresión o el testimonio de la creación humana o de la evolución de la naturaleza y que tienen especial relevancia en relación con la arqueología, la prehistoria, la historia, la literatura, la educación, el arte, la ciencia y la cultura en general y fundamentalmente:

a) Los documentos y demás bienes relacionados con la historia, con inclusión de los de ciencia y técnica, así como la vida de los forjadores de la nacionalidad y la independencia, dirigentes $y$ personalidades sobresalientes, y con los acontecimientos de importancia nacional e internacional;

b) las especies y ejemplares raros o especímenes tipo de la flora y la fauna, así como las colecciones u objetos de interés científico;

c) el producto de las excavaciones y descubrimientos arqueológicos;

ch) los elementos provenientes de la desmembración de los monumentos artísticos o históricos y de los lugares arqueológicos; 
d) los bienes de interés artísticos tales como los objetos originales de las artes plásticas y decorativas, así como las artes aplicadas y el arte popular;

e) los objetos y documentos etnológicos y folklóricos;

f) los manuscritos raros, incunables y otros libros, documentos y publicaciones de interés especial;

g) los archivos incluidos los fotográficos, fonográficos y cinematográficos;

h) los mapas y otros materiales cartográficos, partituras originales o impresas, ediciones de interés especial y grabaciones sonoras;

i) los objetos numismático y filatélico, incluidos los sellos fiscales y otros análogos, sueltos o en colecciones;

j) los objetos etnográficos o instrumentos musicales;

k) todo centro histórico urbano, construcción o sitio que merezca ser conservado por su significación cultural, histórica o social, como establece la Ley 2, de 4 de agosto de 1977, Ley de los Monumentos Nacionales y Locales, y su Reglamento; y

I) todos los demás bienes que el Ministerio de Cultura declare parte del Patrimonio Cultural de la Nación. (Decreto 118/83, Artículo 1)

Indudablemente la estructuración coherente e implementación de un instrumento jurídico para la protección del patrimonio en Cuba como parte de la política de democratización de la cultura y el hecho de que fueran dispuestas como las dos primeras leyes de la Asamblea Nacional del Poder Popular en su condición de órgano supremo del poder del Estado y único con potestad constituyente y legislativa, es el resultado del cúmulo de experiencias que relacionado con este particular se comenzaron a gestar desde las primeras décadas del siglo XX y de la postura del gobierno revolucionario de legitimar el patrimonio de la nación a través de la ejecución de un sistema de leyes que permite el accionar sobre el mismo. 
Trascurridas cuatro décadas de implementada esta legislación se sugiere una revaluación jurídica de la misma atendiendo a las concepciones con que se opera la gestión del patrimonio actualmente en la palestra internacional. No obstante se ha considerado la pertinencia de colocar algunos criterios sobre la base de los postulados de la sociomuseología, que pudieran resultar de utilidad para un futuro análisis, trascendiendo las nociones tradicionales del patrimonio encaradas como "una estrategia conservacionista, y un respectivo horizonte profesional: el de los restauradores, los arqueólogos, los historiadores; en suma, los especialistas del pasado" (García, 1993, p.16), hasta llegar a los que entienden que el patrimonio "cubre, en líneas generales, las prácticas sociales, las tradiciones estéticas y los modos de conocimiento perpetuados en el seno de una comunidad cultural" (Kurin, 2004, p.7))

Partiendo de la definición ofrecida por Kurin, la reflexión está orientada principalmente en llamar la atención de dos aspectos. El primero relacionado con la noción de patrimonio que asume la legislación cubana "aquellos bienes muebles e inmuebles», consecuente con las especificidades declaradas redunda en un marcado carácter objetual. No aparece referencia alguna a la dimensión inmaterial o intangible del patrimonio. Claro está es justo tener en cuenta que en el momento en que se elaboraron y pusieron en vigor estas leyes en Cuba, la concepción operante del patrimonio e incluso oficializada por la UNESCO, y a la cual se acogió la legislación cubana, era justamente concerniente a objetos, colecciones, edificaciones, etc., aunque un poco más adelante, a inicios de la década de los 90 incorporó la categoría de Paisajes Culturales.

El concepto de Patrimonio Cultural Inmaterial $(\mathrm{PCl})$ data del siglo XXI con la Convención para la Salvaguardia del Patrimonio Cultural Inmaterial del 2003, de la cual la Isla es signataria desde el 2004. El hecho es que el marco jurídico ha permanecido inalterable, sin la actualización acorde a las convenciones internacionales a las que se ha suscrito. No obstante resulta innegable que Cuba ha 
tenido desde entonces una meritoria práctica en la gestión y dinamización de las expresiones del PCl figurando dentro de las prioridades estratégicas del MINCULT e instituciones subordinadas, lo que se puede ejemplificar con la declaratoria por la UNESCO en el 2003 de la Tumba Francesa ${ }^{2}$ como Obra Maestra del Patrimonio Oral e Inmaterial de la Humanidad; la Rumba ${ }^{3}$, el Son ${ }^{4}$ y las Lectura de Tabaquería ${ }^{5}$ en el 2012 como Patrimonio Cultural de la Nación y en el 2017 el Punto Cubano ${ }^{6}$ recibió la declaración de Patrimonio Inmaterial de la Humanidad por el Comité Intergubernamental para la Protección y Salvaguardia del Patrimonio Inmaterial.

El segundo aspecto es relativo a la temporalidad establecida por las legislaciones cubanas para realizar declaratorias de patrimonio. Para esta reflexión se tomó como soporte la idea que sustenta que el patrimonio es el “(...) conjunto de todos los bienes o valores, naturales o creados por el Hombre, materiales o inmateriales, sin límite de tiempo ni de lugar, que sean simplemente heredados (...) y conservados para ser transmitidos a los descendientes de las generaciones futuras" (Desvallées \& Mairesse, 2013 , p.74). Al respecto la Resolución no. 3/89 declara como patrimonio cultural todos los bienes que se encuentran en las colecciones de los museos con valor arqueológico, histórico, literario, educacional, artístico, científico y cultural en sentido general, así como los bienes de igual valor que "con una antigüedad

\footnotetext{
${ }^{2}$ Conjunto de expresiones músico-danzarias desarrolladas en las regiones cafetaleras a partir del proceso migratorio de colonos franceses radicados en Haití y sus esclavos de origen africano como consecuencia de la revolución haitiana de 1791 . Se localizan en las provincias de Santiago de Cuba (Sociedad de Tumba Francesa La Caridad de Oriente); Guantánamo (Tumba Francesa Pompadour Santa Catalina de Ricci) y en Holguín (Tumba Francesa de Bejuco).

${ }^{3}$ Expresión músico-danzaria y comunitaria.

${ }^{4}$ Baile en pareja y género musical original de Cuba.

${ }^{5}$ Oficio desarrollado desde el siglo XIX en las factorías de tabaco.

${ }^{6}$ También denominado Punto Guajiro es una expresión poética y musical típica de los campesinos cubanos.
} 
de más de 50 años" se encuentren en poder de personas naturales o jurídicas dentro del territorio nacional.

Así mismo la Resolución no. 4/89 en el segundo de los Resuelvo estipula tal declaratoria para "las obras de artes plásticas ejecutadas por artistas cubanos nacidos entre 1900 y 1960", sobrepasando incluso los cincuenta años de la resolución anterior, lo que implica que a medidas que pasen los años el rango de tiempo se torna más amplio y por tanto la producción resultante de la práctica cotidiana de las comunidades; de lo procesos culturales contemporáneos y de la joven vanguardia artística no tenga ninguna posibilidad de ser considerada patrimonio de la nación. Visto así ambas resoluciones no solamente limitan a determinados marcos temporales al patrimonio sino que no deja margen a que el presente legue también sus valores al futuro.

"El patrimonio no es un capital fijo de una vez y por todas (...). Uno de los grandes peligros de las políticas de conservación es la de tornar imposible la constitución de un patrimonio enriquecido permanentemente de nuevos elementos, fruto de la creatividad natural de la comunidad, suscitado, promovido y favorecido por el proceso de desenvolvimiento (...)" (Varine de, 2012, p.39)

En esencia de lo que se trata es de entender de que como cualquier obra humana puede ser perfectible, se hace necesario revaluar y actualizar el cuerpo legislativo que protege el patrimonio cubano acorde a los nuevos conceptos y a las líneas de pensamiento contemporáneos en cuanto a potenciar su gestión con un enfoque crítico para que pueda marchar parejo a la práctica desarrollada en esta materia. Ya no resultan suficientes los enfoques restrictivos a la conservación y protección, sino que precisamente para garantizar la perdurabilidad en el tiempo es necesario que se preste especial atención a la dinamización y puesta en valor de todas las dimensiones del patrimonio en sus respectivos espacios.

A fines de la década de 1970 estuvieron creadas las condiciones para la creación de una red de museos con la apertura 
de este tipo de instituciones en cada uno de los municipios cubanos. De esta manera fue promulgada la Ley No. 23 De Museos Municipales, del 18 de mayo de 1979.

ARTÍCULO 1: En cada uno de los municipios de la República se creará un museo en el que se conserven y muestren, para su conocimiento y estudio, documentos, fotografías u otros objetos referentes a la historia nacional y local que reflejen las tradiciones del pueblo, los episodios sobresalientes de sus luchas, los hechos y la vida de sus personalidades destacadas en las diversas épocas y lo referente al desarrollo de su economía, su cultura y sus instituciones.

En las capitales de provincia el museo municipal que se cree tendrá, además, carácter provincial.

ARTíCULO 2: Corresponde a las Asambleas Municipales del Poder Popular y a sus dependencias disponer, organizar y ejecutar lo necesario para crear los museos a que se refiere el artículo anterior, a cuyo fin, de manera modesta, utilizarán instalaciones existentes y otros recursos locales disponibles, incluyéndose entre estos, el acondicionamiento de inmuebles de valor histórico o arquitectónico, previa autorización y orientación de las Comisiones de Monumentos.

ARTÍCULO 3: Los museos municipales funcionarán bajo la atención, dirección y control de la Dirección de Cultura de la Asamblea Municipal del Poder Popular correspondiente, subordinada a la orientación técnica y metodológica del Ministerio de Cultura.

ARTICULO 4: Corresponde al Ministerio de Cultura impartir las instrucciones y dictar las normas técnicas y metodológicas para la instalación y funcionamiento de los museos municipales".

La apertura masiva de museos amparados por una ley constituyó, sin lugar a dudas, un paradigma en el contexto cultural 
cubano con la fundación de alrededor de 217 instituciones museales durante los tres primeros años de la década de 1980, proceso que a decir de Marta Arjona (1986) constituyó la iniciativa cubana para el desarrollo de la museología popular. Ello se tradujo en el establecimiento de vínculos entre los museos y la comunidad desde el momento en que los miembros de la comunidad se convirtieron en los principales aportadores del patrimonio que conformarían las colecciones, alcanzando una significación extraordinaria en lo que a identificación del patrimonio de las diferentes localidades y el fortalecimiento de los valores identitarios nacionales se refiere.

No cabe dudas de que la esencia de la Ley no. 23 fue la de legitimar, proteger y conservar el patrimonio de todas las localidades cubanas a través de los museos municipales que funcionarían como museos comunitarios, lo que quedó sintetizado claramente en el primer artículo. No obstante consideramos la pertinencia de un acercamiento a algunos conceptos de museo comunitario para entender la dinámica de este proceso en el contexto cubano. Acorde a Camarena y Morales (2009, p.5) un museo comunitario "es creado por la misma comunidad: es un museo "de" la comunidad, no elaborado externamente "para" la comunidad". En tanto Hugues de Varine remite a un concepto con mucho más alcance:

"Como el propio desarrollo, el museo de comunidad es más bien descrito como proceso. Él ciertamente no es una institución o una estructura acabada. Es un ser vivo como la propia comunidad, en constante movimiento para adaptarse a los cambios que acontecen en ella y en su ambiente, sea él regional, nacional o global" (Varine de, 2014, pp. 28-29)

Partiendo de la coincidencia que se asume con estos criterios que apuntan a que un museo comunitario debe ser fruto de una concepción y construcción colectiva desde la propia comunidad, resulta oportuno reflexionar en ciertos aspectos que desviaron un tanto el propósito inicial de la Ley 23. Por una parte la manera como 
se orientó el proceso de planeamiento de los discursos museológicos y museográficos regidos por un patrón estandarizado a partir de un esquema elaborado acorde a las etapas en que se estudia la historia de Cuba, que no siempre concomitan con las de los contextos locales, y la concepción y ejecución de los montajes a cargo del personal especializado de la DNPC.

Por otro lado, consecuente con las nociones iniciales, las comunidades no participaron en la selección de los inmuebles, lo cual estuvo a cargo de las instancias gubernamentales; ni en determinar cómo deseaban ser representados en las exposiciones. Incluso derivado de la estandarización de los discursos museológicos en algunas de estas instituciones se expusieron temáticas que no se relacionaban con la historia de la comunidad.

No obstante el espíritu de la Ley no. 23 gravitó y se puede afirmar que el amplio proceso de participación social que tuvo lugar, fundamentado principalmente en las donaciones de objetos resultó de extrema importancia para la estructuración de las colecciones que conforman el acervo patrimonial de los museos cubanos y más allá de eso constituyó expresión del proceso de democratización de la cultura, resultando en tal sentido un aporte de la Revolución a la museología en Cuba y reconocida por organismos internacionales como el Movimiento Internacional de la Nueva Museología (MINOM) ${ }^{7}$.

Bajo esta ley operaron los museos en Cuba por espacio de tres décadas, siendo derogada la misma en el 2009 y sustituida por la Ley no. 106. Algunos autores que han incursionado en el tema de las legislaciones cubanas sobre el patrimonio cultural consideran que la derogación de la Ley no. 23 se debió a que:

“(...) aunque la intensión fue loable y resultaron experiencias positivas; el museo municipal no debió

7 Durante la XVI Conferencia Internacional del MINOM, celebrada en La Habana del 6 al 11 de octubre del 2014 fue refrendado el impacto social de la Ley no. 23 De la creación de los Museos Municipales en Cuba. (MINOMICOM. Declaración de La Habana, 2014). 
estereotiparse a lo largo del país, ya que todos los territorios no cuentan con la riqueza artística o histórica, e incluso, con los testimonios que validen su patrimonio. De modo que en varios de los casos no se expresaba como una opción atractiva o al menos representativa de la comunidad, y carecía de un criterio museológico fundamentado" (Carrillo, 2015, p.45)

Respecto a este criterio no coincidimos con los argumentos ofrecidos por Carrillo, a nuestro modo de ver muy absolutos. Si algo evidenció la Ley no.23 fue precisamente la riqueza de acervos históricos, culturales y naturales existentes en cada una de la localidades cubanas de las que se nutrieron los museos surgidos a su amparo incluso en pequeñas comunidades, a través del elevado nivel de piezas aportadas por las mismas. O sea el estereotipo no se debió a la inexistencia de acervos patrimoniales locales, sino a los enfoques y concepciones museológicas practicadas en Cuba en ese período. De modo que sobre este particular se continúa insistiendo en que el esquema de los discursos museológicos enmarcados en las etapas en que se estudia la historia nacional respondió básicamente a la visión occidentalista ${ }^{8}$ con que se enfocaron por largo tiempo los estudios y la enseñanza de la historia patria, momentos en que aún no se consideraba como parte de la misma el conjunto de las historias locales.

$\mathrm{Si}$ bien es cierto que en ocasiones las exposiciones no se ajustaron a las realidades locales, lo cual consideramos una limitación no de la ley propiamente sino de la práctica, se entiende que la derogación de la referida ley obedeció más bien a que después de treinta años de creada la red de museos en Cuba emergió la necesidad de restructurar y consolidar el funcionamiento interno de estas instituciones y de ampliar el alcance hacia todos los

${ }^{8}$ Se refiere a la visión con que la historiografía cubana enfocó por largo tiempo los estudios históricos, sin que en ellos se destacaran los del nivel local, centrando la atención en los acontecimientos ocurridos en la región occidental del país. 
organismos y entidades con responsabilidad sobre alguna de las dimensiones del patrimonio, a través de un mecanismo articulador que trazara las directrices metodológicas generales para una gestión más eficaz del mismo.

Por otra parte es necesario atender a la situación en que quedaron mucho de los museos cubanos como consecuencia del Período Especial, con insuficiencias en la disponibilidad de recursos para su mantenimiento que interrumpió la actualización de los discursos expositivos y de la dinámica museológica en general provocando el cierre de un significativo número de estas instituciones en todo el país.

La Ley No. 106, Del Sistema de Museos de la República de Cuba, del 13 de agosto de 2009, aprobada por la Asamblea Nacional del Poder Popular; por Acuerdo VII -25, estipuló la organización del Sistema Nacional de Museos de la República de Cuba (SNMRC) como mecanismo de integración y articulación para la mejor protección de los bienes culturales patrimoniales y museales que se encuentran en dichas instituciones y sus extensiones, lo cual consideramos como la principal contribución de la misma. Esta ley se hizo efectiva a través del Decreto 312 dictado por el Consejo de Ministros y aprobado el 8 de abril del 2013. En los 18 capítulos y 80 artículos se dispone el funcionamiento de los museos cubanos.

Los artículos 3 y 4 del Capítulo II de esta nueva ley son contentivos de los principios básicos sobre los que se sustenta la actividad museal en Cuba y rige la tipología de estas instituciones. Con la derogación de la ley no.23 y la puesta en vigor de la 106 se produjo el cambio de nomenclatura de Red nacional de Museos (RNM) por Sistema nacional de museos de la república de Cuba (SNMRC).

“ARTíCULO 3.-El Sistema Nacional de Museos de la República de Cuba es el mecanismo de integración y promoción de la cultura, que tiene como finalidad lograr la protección, conservación y divulgación del patrimonio cultural de la nación, así como contribuir a la formación de valores patrióticos, éticos y estéticos en la población, a 
partir de la aplicación de principios, normas y procedimientos que rigen la actividad.

ARTíCULO 4.-El Sistema Nacional de Museos de la República de Cuba está integrado por los museos nacionales, específicos, provinciales y municipales, los que por la naturaleza de sus colecciones pueden ser generales y especializados en arte, historia, arqueología, ciencias naturales, ciencia y tecnología, etnografía, antropología y otras especialidades".

Con el transcurso del tiempo comenzaron a surgir otros museos bajo el auspicio de diferentes entidades estatales y unido a ello emergió una perentoria necesidad de alcanzar la vinculación de todas las instituciones de este tipo pertenecientes o no al MINCULT y desde esa perspectiva la Ley 106 tiene una esencia integradora, la que designa, además, al Consejo Nacional de Patrimonio Cultural (CNPC) como entidad encargada de la asesoría metodológica de la actividad museológica de todo el SNMRC. Esto ha incidido sustancialmente en la paulatina expansión de los horizontes conceptuales en torno al patrimonio cultural.

"Es mi convicción que para la ejecución de las funciones de preservación del patrimonio cultural y natural de nuestro país son esenciales: la participación activa de la comunidad, el vínculo con instituciones docentes y científicas, organismos y otras entidades, así como la movilización social en torno de la salvaguardia de aquello que nos identifica y nos da sentido de pertenencia como nación. Por tanto, la labor cultural y comunicativa en los museos debiera comprender todas aquellas acciones que estas instituciones desarrollan para, en todos los espacios posibles, se establezcan nexos culturales y educativos con el público" (García, 2014, p.73)

Si bien coincidimos en la importancia de esta ley de integrar en un mismo sistema todas las instituciones museales existentes en 
Cuba como mecanismo de garantizar una mayor y mejor operatividad del patrimonio con el enfoque esencial de patrimonio de la nación con independencia de la administración bajo la que se encuentre, y como instrumento de reglamentación de las funciones de los museos, consideramos que la misma no trasciende lo concerniente a las orientaciones metodológicas para el trabajo técnico en los museos, aspecto que debe tenerse en cuenta para una posible reevaluación de la misma.

\section{BIBLIOGRAFÍA}

Alfonso, F. (2008). La Oficina del Historiador de la Ciudad de La Habana y la defensa del Patrimonio Histórico de La Habana. In: Curso sobre Manejo y Gestión de Centros Históricos, Conferencia 2. La Habana.

Arias, L. (2014). La legislación para la protección del Patrimonio en Cuba y su aplicación en las casas-museos Abel Santa María, Hurón Azul y José Lezama Lima. Tesis para la obtención del grado de máster en Conservación del Patrimonio Cultural, perfil Museología, Centro de Estudios de Conservación, Restauración y Museología, ISA, orientada por la MSc. María Mercedes García Santana, La Habana.

Arjona, M. (1986). Patrimonio Cultura e identidad Nacional. La Habana: Editorial Letras Cubanas.

Asamblea Nacional del Poder Popular (1976). Constitución de la República de Cuba. In: Gaceta Oficial de la República de Cuba, Edición Especial No.2, 24 de Febrero.

Asamblea Nacional del Poder Popular (ANPP) (2009). Ley No. 106 Del Sistema Nacional De Museos de la República de Cuba, 1 De Agosto. In: Gaceta Oficial de la República de Cuba, Edición Extraordinaria, Número 28, De Fecha 13 de agosto de 2009.

Asamblea Nacional del Poder Popular (ANPP) (2013). Reglamento De La Ley No. 106 Del Sistema Nacional de Museos de la República de Cuba, 8 De Abril. In: Gaceta Oficial de la República 
de Cuba, Edición Ordinaria, Número 24, De Fecha 2 de mayo de 2013.

Barrial, A., \& Barrial, A. (2012). La política cultura cubana en la década de 1960 en Cuba, Contribuciones a la Ciencias Sociales. In: http://:wwweumed.net/rev/cccss/201/ . Consultado el 5 de abril de 2016.

Camarena, C. \& Morales, T. (2009). Manual para la creación y desarrollo de museos comunitarios. New York: Fundación Interamericana de Cultura y Desarrollo (ICDF).

Cantón, J. \& Duarte, M. (2006). Cuba 42 años de Revolución. Cronología histórica 1959 - 1982 (Tomo I). La Habana: Editorial de Ciencias Sociales.

Carrillo, I. (2015). Reflexiones oportunas a medio siglo de museo y museología en Cuba. In: Actas del XXIII ICOFOM LAM. Panamá: ICOFOM LAM, pp. 38-54.

Castro Ruz, F. (1961). Palabras a los intelectuales. Discursos pronunciados los días 16, 23 y 30 de junio en el Salón de Actos de la Biblioteca Nacional. Ciudad de La Habana.

Constitución de 1940, del 1 de julio, Guáimaro, Camagüey.

Desvallées, A., \& Mairesse, F. (Eds.). (2013). Conceptos claves de la Museología. Sao Paulo: Comité Brasileño del Consejo Internacional de Museos: Pinacoteca del Estado de Sao Paulo: Secretaria de Estado de la Cultura.

García, Juan M. (1964). El Primer Director del Centro Regional de la Unesco. In: Separata de la Revista Universidad de La Habana, Julio-Octubre, pp.3-39. La Habana: Universidad de La Habana.

García, N. (1993). Los usos sociales del patrimonio cultural. In: Florescano, E. [Comp.]. El patrimonio Cultural de México. México: F.C.E

García, J. (2014). La labor museológica de la Revolución cubana y el proceso de transformación en la proyección social de los museos en Cuba. In.: Intervención, Año 5, Núm. 9, Enero-junio, pp.65-75. 
Kurin, R. (2004). Los museos y el patrimonio inmaterial: ¿cultura viva o muerta? In: Boletín del Consejo Internacional de Museos, Vol. 57, No. 4. París: ICOM.

López, F. (2013). Estado nacional, dependencia y resistencia (18991952). In.: López, F.; Mencía, M.; \& Álvarez, P. Historia de Cuba 1899-1958 (Primera reimpresión, pp.2-257). La Habana: Editorial Pueblo y Educación. (Publicación original 2012).

Rigol, I. \& Rojas, A. (2012). Conservación patrimonial: teoría y crítica. La Habana: Editorial UH.

Varine, $\mathrm{H}$. de (2012). Las raíces del futuro. El patrimonio al servicio del desenvolvimiento local. Porto Alegre: Medianiz.

Varine, H. de (2014). El museo comunitario como proceso continuado. In: Cuadernos del CEOM - Museologia Social, Año 27, no.

41 , pp. 25-35. https://bell.unochapeco.edu.br/revistas/index.php/rcc/.../1495 . Consultado 12 de abril de 2018. 
